\title{
Evaluation of Clinical Severity, Scalp Involvement Severity, and Nail Involvement Severity in Psoriasis Patients
}

Psoriasis Hastalarında Klinik Şiddet, Saçlı Deri Tutulum Şiddeti ve Tırnak Tutulum Şiddetinin Değerlendirilmesi

\section{Şirin Çelik', (D) Nahide Onsun², (D) Özlem Su Küçük²}

1-Estethica Levent Hastanesi, Dermatoloji Anabilim Dalı, İstanbul, Türkiye, 2- Bezmialem Vakıf Üniversitesi Hastanesi, Dermatoloji Anabilim Dalı, İstanbul, Türkiye.

\begin{abstract}
Aim: Psoriasis is a chronic immune-mediated skin disease that can progress with skin, nail, and joint involvement. Skin lesions adversely affect the life quality due to both itching and development of aesthetical anxiety. Nail and joint lesions also reduce life quality in terms of aesthetics and functionality. Our study aimed to determine the relationship between the severity of scalp and nail involvement with the severity of skin lesions in psoriasis patients.

Materials and Methods: This prospective study included a total of 267 psoriasis (plaque and guttate type) patients aged between 18 and 70 years old who were being followed up and treated at the psoriasis outpatient clinic between 2010 and 2011. The psoriasis severity index was calculated to determine the disease severity of these patients who were diagnosed clinically or histopathologically. Scalp involvement severity was assessed by the Psoriasis Scalp Severity Index, and the Nail Psoriasis Severity Index scoring evaluated nail involvement severity.

Correlation between variables was evaluated with the Pearson correlation test, and the difference between these correlations was assessed with the $Z$ test.

Results: Of the 267 patients included in the study, 135 were male, and 132 were female. The mean age of the patients was 43.64 (18-70). Of the patients, 106 received topical therapy, 103 received systemic treatment, 53 received biological agent therapy, and five received phototherapy. While 173 of the patients had a plaque, and 84 had guttate lesions, ten did not have lesions. A significant relation was found between the Psoriasis Severity Index values and the Psoriasis Scalp Severity Index values of patients $(p<0.001)$. A meaningful relationship was found between the Psoriasis Severity Index values and the Nail Psoriasis Severity Index values of patients $(p<0.001)$. However, no significant relation was found between the Psoriasis Scalp Severity Index values and the Nail Psoriasis Severity Index values of patients $(p=0.440)$.

Conclusion: As the clinical severity of the disease increases in psoriasis patients, the scalp and nail involvement severity increases. There is no relationship between the severity of scalp involvement and nail involvement.
\end{abstract}

ÖZET

Amaç: Psoriasis deri, tırnak ve eklem tutulumu ile seyredebilen kronik immün aracıl bir cilt hastalı̆gldır Cilt lezyonları gerek kașıntılı olmalarından gerek de estetik kaygı olușturmalarından ötürü kişinin yașam kalitesini kötü yönde etkilemektedirler. Yine tırnak ve eklem lezyonları da estetik ve fonksiyonel açıdan kişinin yaşam kalitesini düşürür. Çalışmamızdaki amaç psoriasis hastalarında, saçlı deri tutulum şiddeti ve tırnak tutulum şiddetinin psoriasis cilt lezyonlarının şiddeti ile ilişkisini saptamaktır.

Gereç ve Yöntem: Bu prospektif çalışmaya 2010 ve 2011 ylları arasında psoriasis polikliniğinde takip ve tedavileri devam etmekte olan 18-70 yaş arası toplam 267 psoriasis (plak ve guttat tip) hastası alındı. Klinik veya histopatolojik olarak tanıları konmus olan bu hastaların hastalık siddetini belirlemek için psoriasis alan şiddet indeksi hesaplandı. Saçlı deri tutulum şiddeti Psoriasis Saçlı Deri Şiddeti İndeksi ile tırnak tutulum şiddeti ise Tırnak Psoriasisi Şiddet Indeksi skorlamast ile değerlendirildi.

Değişkenler arasındaki korelasyon Pearson korelasyon testi ile, bu korelasyonlar arasındaki fark ise $Z$ testi ile değerlendirildi.

Bulgular: Çalıșmaya alınan 267 hastanın 135'i erkek, 132 'si kadın idi. Hastaların yas ortalaması 43,64 (18-70) idi. Hastaların 106'sı topikal tedavi, 103 'ü sistemik tedavi, 53 'ü biyolojik ajan tedavisi, beşi fototerapi almaktaydl. Hastaların 173'ü plak, 84'ü guttat lezyona sahipken, onunun lezyonu yoktu. Hastaların Psoriasis Alan Şiddet Indeks değerleri ile Psoriasis Saçlı Deri Şiddeti Indeksi arasında anlamlı bir ilişki saptand $(p<0,001)$. Hastaların Psoriasis Alan Şiddet İndeks değerleri ile Tırnak Psoriasisi Şiddet Indeksi değerleri arasında anlamlı bir ilișki saptandı $(p<0,001)$. Ancak hastaların Psoriasis Saçlı Deri Şiddeti Indeksi değerleri ile Tırnak Psoriasisi Şiddet İndeksi değerleri arasında anlamlı bir ilişki saptanmadı $(p=0,440)$.

Sonuç: Psoriasis hastalarında hastalı̆̆ın klinik şiddeti arttıkça saçlı deri tutulum şiddeti ve tırnak tutulum şiddeti artmaktadır. Saçlı deri tutulum şiddeti ile tırnak tutulum şiddeti arasında bir ilişki yoktur.
Key Words:

Psoriasis,

Psoriasis Severity Index,

Psoriasis Scalp Severity Index,

Nail Psoriasis Severity Index

Anahtar Kelimeler:

Psoriasis,

Psoriasis Alan Şiddet Indeksi,

Psoriasis Saçlı Deri Şiddeti Indeksi,

Tırnak Psoriasisi Şiddet İndeksi,

Correspondence: Uzm. Dr. Şirin Çelik, Estethica Levent Hastanesi, Dermatoloji Anabilim Dalı, İstanbul, Türkiye,

E-Mail: sirincelik.dr@gmail.com Tel: 05307858444

Cite this article as: Çelik Ş, Onsun N, Küçük ÖS. Evaluation of Clinical Severity, Scalp Involvement Severity, and Nail Involvement Severity in Psoriasis Patients. Phnx Med J. 2020;2(1):98-101 


\section{Şirin et al.}

\section{GIIRIŞ VE AMAÇ}

Psoriasis, çeşitli klinik biçimlerde ortaya çıkabilen, genel popülasyonda \% 1-3 oranında görülen kronik seyirli, immün aracılı bir hastalıktır (1). Plak psoriasis, püstüler psoriasis, guttat psoriasis, eritrodermik psoriasis ve inverse psoriasis gibi farklı formları bulunup deri, tırnak ve eklem tutulumu ile seyreder. Deri tutulumunun şiddeti "Psoriasis Alan Şiddet İndeksi" ile skorlanarak hesaplanır.

Saçlı deri tutulumu psoriasis hastalarının \%40-90'ında görülmektedir (2). Hafiften şiddetliye değişken bir klinik göstermekle birlikte gerek kaşıntılı bir tablo olması gerek kozmetik açıdan rahatsılık verici bir durum olması hastaların yaşam kalitesini oldukça lezyonlarının şiddeti ile ilişkisinin değerlendirilmesi amacıyla prospektif olarak tasarlandı. Bezmialem Vakıf Üniversitesi Etik Kurulunun 05.08.2011 tarih ve 10/6 kararı ile çalışmaya başlandı.

Çalışma 2010-2011 yılları arasında Bezmi Alem Vakıf Üniversitesi (BAVÜ) Tıp Fakültesi Deri ve Zührevi Hastalıkları Ana Bilim Dalı'nda gerçekleştirildi. Çalışmaya BAVÜ psoriasis polikliniğinde takip ve tedavileri devam etmekte olan 18-70 yaş arası toplam 267 psoriasis (plak ve guttat tip) hastası alındı. Klinik veya histopatolojik olarak tanıları konmuş hastalar topikal steroid/kalsipotriol, konvansiyonel tedaviler (asitretin, metotreksat, siklosporin), biyolojik ajan (etanercept, infliximab, adalimumab) tedavilerini

Tablo 1: PAȘİ kriterleri

\begin{tabular}{|c|c|c|c|c|c|c|c|}
\hline SKOR & $\mathbf{0}$ & 1 & 2 & 3 & 4 & 5 & 6 \\
\hline ERITEM=E & YOK & HAFİF & ORTA & ŞİDDETLİ & ÇOK ŞİDDETL்̇ & & \\
\hline İNFİLTRASYON=İ & YOK & HAFİF & ORTA & ŞİDDETLİ & ÇOK ŞİDDETLI் & & \\
\hline DESKUAMASYON=D & YOK & HAFİF & ORTA & ŞİDDETLI & ÇOK ŞİDDETLİ & & \\
\hline TUTULAN ALAN=A & $\% 0$ & $\% 0-10$ & $\% 10-30$ & $\% 30-50$ & $\% 50-70$ & $\% 70-90$ & $\% 90-100$ \\
\hline
\end{tabular}

Tablo 2: PAȘİ formülü hesaplama

\begin{tabular}{|l|l|l|l|l|}
\hline & Baş & Üst ekstremite & Gövde & Alt ekstremite \\
\hline PAŞ $=$ & $0,1 \mathrm{x}(\mathrm{E}+\mathrm{I}+\mathrm{D})^{+}$ & $0,2(\mathrm{E}+\mathrm{I}+\mathrm{D}) \mathrm{A}^{+}$ & $0,3(\mathrm{E}+\mathrm{I}+\mathrm{D}) \mathrm{A}+$ & $0,4(\mathrm{E}+\mathrm{I}+\mathrm{D}) \mathrm{A}$ \\
\hline
\end{tabular}

etkilemektedir. Psoriasiste saçlı deri tutulumu eritem, skuam ve plaklar şeklinde olabilir. Saçlı deri tutulum şiddeti "Psoriasis Saçlı Deri Şiddeti İndeksi" (Psoriasis Scalp Severity İndex) (3) veya "Videodermoskopi Saçli Deri Psöriazisi Şiddet Indeksi" (Videodermoscopy Scalp Psoriasis Severity İndex) (4) ile skorlanarak hesaplanır. Videodermoskopi Saçlı Deri Psöriazisi Şiddet İndeksi daha çok klinik olarak fark edilmesi kolay olmayan hafif ve orta şiddetli saçlı deri tutulumunda kullanılan bir yöntemdir.

Psoriasiste tırnak tutulumu tırnak plağı tutulumu sonucu ortaya çıkan yağ damlası, onikoliz, splinter hemoraji, hiperkeratoz ve tırnak matriksi tutulumu sonucu ortaya çıkan pitting, lökonişi, lunulada kırmızı noktalanma ve tırnakta ufalanma bulgularından oluşur. Tirnak tutulumu psoriasisli hastaların yarısından fazlasında ortaya çıkar. Yaşamları boyunca tutulum oranı ise \%80-\%90 arasındadır $(5,6)$. Psoriyatik tırnak tutulum şiddeti "Tırnak Psoriasisi Şiddet İndeksi”" (Nail Psoriasis Severity Index) ile skorlanarak hesaplanır.

Amacımız; kliniğimizde gördüğümüz psoriasis hastalarında, saçlı deri tutulum şiddeti ve tırnak tutulum şiddetinin psoriasis cilt lezyonlarının şiddeti ile ilişkisini saptamaktır.

\section{MATERYAL METOD}

Çalışmamız psoriasis hastalarında, saçlı deri tutulum şiddeti ve tırnak tutulum şiddetinin psorisis cilt mono/kombine terapi olarak almaktayd.

Klinik veya histopatolojik olarak tanıları konmuş 267 psoriasis hastasının hastalık şiddetini belirlemek için psoriasis alan şiddet indeksi (PAŞi) hesaplandı (Tablo 1,2). Saçlı deri tutulum şiddeti Psoriasis Saçlı Deri Şiddeti İndeksi (PSŞİ) ile değerlendirildi. Tırnak tutulum şiddeti Tırnak Psoriasisi Şiddet İndeksi (TPŞİ) skorlaması ile değerlendirildi.

\section{Saçlı deri tutulum şiddeti olan PSŞİ şu şekilde hesaplandı:}

Saçlı derideki eritem, infiltrasyon ve deskuamasyon 04 arasında skorlanarak toplandı. Saçlı deride tutulan alan 0-6 arasında skorlanarak elde edilen skor daha önce elde edilen toplamla çarpıldı. Sonuçta elde edilen toplam 0-72 arasında değişmektedir (3).

PSŞİ $=(\mathrm{E}+\mathrm{I}+\mathrm{D}) \mathrm{xA}$

\section{Kullanılan TPŞİ skoru :}

Her bir tırnak horizontal ve longitudinal olarak 4 kadrana ayrıldı. Her tırnak yatağı bulgusu için bir tırnağa 0-4 arası skor verildi. Her tırnak matriksi bulgusu için bir tırnağa 0-4 arası skor verildi. Tüm tırnaklarda hesaplanan tüm skorlar toplanarak total NAPŞI skoruna ulaşıldı $(7,8)$.

1. Tirnak matriksi: Her bir kadranda bulunan tırnak matriks psoriasisi bulgularının her biri ayrı ayrı (pitting, lökonişi, lunulada kırmızı noktalanma, tırnak plağı parçalanması) değerlendirildi. Bulgu yoksa 0, bir 
Tablo 3: Kullanılan tedavi şekilleri

\begin{tabular}{|l|c|}
\hline Tedavi şekli & $\mathbf{n}$ \\
\hline Topikal Tedavi & 106 \\
Oral Sistemik Tedavi & 103 \\
Biyolojik Ajan Tedavi & 53 \\
Fototerapi & 5 \\
Total & 267 \\
\hline
\end{tabular}

Tablo 4: Hastalarda bulunan lezyon tipleri

\begin{tabular}{|l|c|c|}
\hline Lezyon şekli & $\mathbf{n}$ & $\mathbf{\%}$ \\
\hline Plak & 173 & 64,8 \\
Guttat & 84 & 31,5 \\
Lezyon Yok & 10 & 3,7 \\
Total & 267 & 100,0 \\
\hline
\end{tabular}

Tablo 5: Hastaların PAŞİ, PSŞİ ve TPŞİ ortalamaları

\begin{tabular}{|l|c|c|c|}
\hline & Ortalama & SD & $\mathbf{n}$ \\
\hline PAŞİ & 3,43 & 3,75 & 267 \\
PSŞ่ & 0,32 & 0,51 & 267 \\
TPŞİ & 11,83 & 13,43 & 267 \\
\hline
\end{tabular}

kadranda varsa 1, iki kadranda varsa 2, üç kadranda varsa 3, dört kadranda varsa 4 verildi.

2. Tırnak yatağı: Her bir kadranda bulunan tırnak yatak psoriasisi bulgularının herbiri ayrı ayrı (onikoliz, splinter hemoraji, subungual hiperkeratoz, yağ lekesi) değerlendirildi. Bulgu yoksa 0 , bir kadranda varsa 1, iki kadranda varsa 2, üç kadranda varsa 3 , dört kadranda varsa 4 verildi.

3. Her bir tırnak matriks için ve tırnak yatağı için skorlandırıldı. Her bir tırnak için total skorlama (0-8) arasındadır.

4. Bütün tırnak skorları toplanarak total skor hesaplandı. Total skor 0-80 idi. Eğer ayak tırnakları katılsayd1 0-160 arası olacakt1.

Değişkenler arasındaki korelasyon Pearson korelasyon testi ile, bu korelasyonlar arasındaki fark ise $\mathrm{Z}$ testi ile değerlendirildi.

\section{BULGULAR}

Çalışmaya alınan 267 hastanın 135'i erkek, 132'si kadın idi. Hastaların yaş ortalaması 43,64 (18-70) idi. Hastaların 106'sı topikal tedavi, 103'ü sistemik tedavi, 53'ü biyolojik ajan tedavisi, 5'i fototerapi almaktaydı (Tablo 3). Hastaların 173'ü plak, 84'ü guttat lezyona sahipken, 10'unun lezyonu yoktu (Tablo 4).

Hastaların PAŞİ ortalaması 3,43, PSŞİ ortalaması 0,32, TPŞİ ortalaması 11,83 idi (Tablo 5).

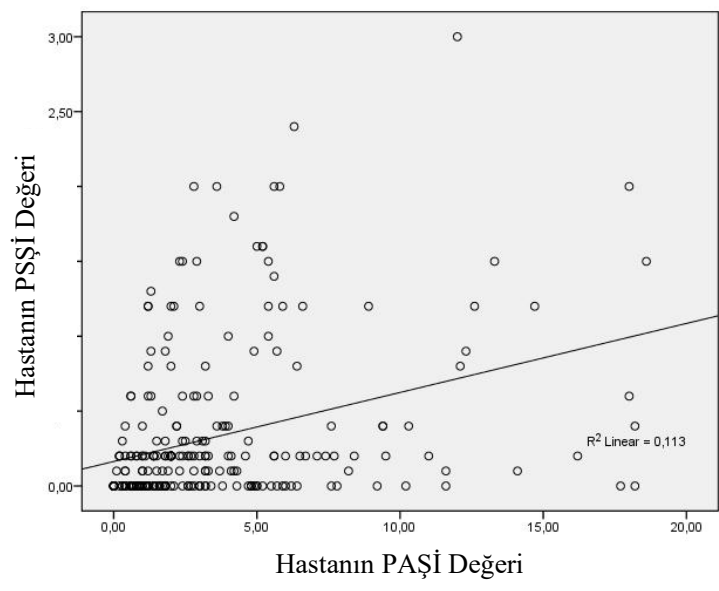

Şekil 1: Hastaların PAŞİ ve PSŞİ değerleri arasındaki ilişki

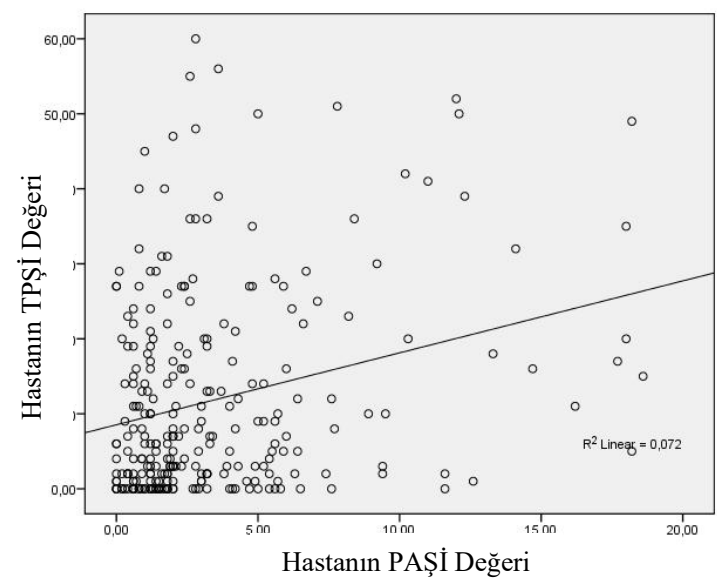

Şekil 2: Hastaların PAŞİ ve TPŞİ değerleri arasındaki ilişki

Hastaların PAŞİ değerleri ile PSŞI değerleri arasında anlamlı bir iliş̧i saptandı $(p<0,001)$ (Şekil 1).

Hastaların PAŞI değerleri ile TPŞI değerleri arasında anlamlı bir ilişki saptandı $(p<0,001)$ (Şekil 2).

Hastaların NAPSİ değerleri ile PSSİ değerleri arasında anlamlı bir ilişki saptanmadı $(\mathrm{p}=0,440)$.

\section{TARTIŞMA}

Psoriasis deri, tırnak ve eklem tutulumu ile seyredip deri tutulumu saçlı deri dâhil tüm vücudu kapsamaktadır. Saçlı deri tutulumu şiddeti değişken olup, tek başına olabileceği gibi diğer vücut bölgelerinin tutulumuyla birlikte de görülebilir. Tüm vücut psoriasis şiddeti ile saçlı deri tutulum şiddeti arasında bir korelasyon olup olmadığı ile ilgili literatürde herhangi bir çalışmaya rastlamadık. Biz çalışmamızda hastaların psoriasis şiddeti (PAŞi) ile saçlı deri tutulum şiddeti (PSŞSif) arasında oldukça anlamlı bir ilişki saptadık $(\mathrm{p}<0,001)$. 


\section{Şirin et al.}

Psoriasis cilt tutulum şiddeti ile tırnak tutulum şiddeti arasındaki ilişkiyi inceleyen çalışmalar literatürde mevcuttur. Jones ve arkadaşları PAŞİ ile TPŞİ arasında anlamlı bir korelasyon saptamışlardır $(p<0,001)$ (9). Özden ve arkadaşları tırnak tutulum şiddeti ile PAŞİ skorlarının birbiriyle orta derecede korelasyon gösterdiğini saptamıştır (10). Biz de çalışmamızda hastaların PAŞİ değerleri ile TPŞİ değerleri arasında anlamlı bir ilişsi saptadık ( $\mathrm{p}<0,001)$.

Sonuç olarak psoriasis hastalarında hastalığın klinik şiddeti arttıkça saçlı deri tutulum şiddeti ve tırnak tutulum şiddeti artmaktadır. Saçlı deri tutulum şiddeti ile tırnak tutulum şiddeti arasında bir ilişki yoktur.

\section{Çıkar İlişkisi}

Tüm yazarlar çıkar çatışması olmadığını beyan eder.

\section{KAYNAKLAR}

1. Gülekon A, Adışen E. Psoriasis ve Komorbiditeler. Türkderm. 2008;42(2 Özel Say1):23-25.

2. Farber, EM, Nall, L. Natural history and treatment of scalp Psoriasis. Cutis. 1992; 49:396-400.

3. Kircik LH, Kumar S. Scalp Psoriasis. JDD. 2010;9(8 Suppl):101-5.

4. Rossi A, Mandel VD, Garelli V, et al. Videodermoscopy scalp psoriasis severity index (VSCAPSI): a useful tool for evaluation of scalp psoriasis. Eur J Dermatol. 2011;21(4):546-551.

5. Jiaravuthisan MM, Dasseville D, Vender RB et al. Psoriasis of the nail: anatomy, pathology, clinical presentation, and a review of the literature on therapy. J Am Acad Dermatol. 2007;57:1-27.

6. Augustin M, Krüger K, Radtke MA et al. Disease severity, quality of life and health care in plaque-type psoriasis: a multicenter crosssectional study in Germany. Dermatology 2008; 216: 366-372.

7. Rich P, Scher RK. Nail Psoriasis Severity Index: A useful tool for evaluation of nail psoriasis. J Am Acad Dermatol 2003;49:206-12.

8. Rich P, Griffiths C, Reich $\mathrm{K}$ et al. Baseline nail disease in patients with moderate to severe psoriasis and response to treatment with infliximab during 1 year. J Am Acad Dermatol. Feb 2008; 58: 224-231.

9. Jones SM, Armas JB, Cohen MG et al. Psoriatic arthritis: outcome of disease subsets and relationship of joint disease to nail and skin disease. Br J Rheumatol. 1994;33(9):834-839.

10. Güler Özden M, Çelık F, Aydın F ve ark. Psöriyazis Olgularında Tırnak Tutulum Oranları ve NAPSI-PASI Korelasyonu. Turkiye Klinikleri J Dermatol. 2010;20(2):55-9. 